\title{
Effects of a vitamin D analog, alfacalcidol, on bone and skeletal muscle in glucocorticoid-treated rats
}

\author{
Naohisa Miyakoshi, Hiroshi Sasaki, Yuji Kasukawa, Keiji Kamo, and Yoichi Shimada \\ Department of Orthopedic Surgery, Akita University Graduate School of Medicine, Akita 010-8543, Japan \\ (Received 17 August 2010; and accepted 2 September 2010)
}

\begin{abstract}
Glucocorticoids cause secondary osteoporosis and myopathy. The efficacy of vitamin D on osteoporotic fractures is thought to be through direct effects on bone and indirect effects on muscles that help to prevent falls. However, effects of vitamin D on muscles under glucocorticoid treatment remain unclear. Six-month-old female Wistar rats were randomized to four groups: vehicletreated controls; a prednisolone (PSL)-administered group (PSL group); an alfacalcidol-administered group (D group); and a group administered both PSL and alfacalcidol (PSL+D group). After a 4-week treatment period, maximum contractile strength and strength decrement index (SDI), an indicator of muscle fatigue, were measured in the calf muscle by electrical stimulation of the sciatic nerve. Cross-sectional area (CSA) of muscle fibers in the tibialis anterior muscle and bone mineral density (BMD) of the femur were evaluated. The PSL group showed significantly lower muscle strength, BMD and CSA of muscle fibers, and significantly higher SDI compared to the other three groups $(P<0.05)$. No significant differences were observed in any of these parameters among control, D, and PSL+D groups. These results suggest that in glucocorticoid-treated rats, alfacalcidol preserved not only BMD, but also muscle strength and muscle volume, and prevented muscle fatigue.
\end{abstract}

Due to their potent anti-inflammatory and immunosuppressive properties, glucocorticoids are used to treat numerous clinical disorders. Glucocorticoidinduced osteoporosis is the most common form of secondary osteoporosis, with fractures occurring in as many as $30-50 \%$ of patients receiving long-term glucocorticoid therapy (15). Evidence suggests that the fracture threshold in patients with glucocorticoidinduced osteoporosis is lower than that in patients with primary osteoporosis (45). Three mechanisms for the increased fracture rate in glucocorticoid-induced osteoporosis have been suggested: apoptosis of osteoblasts and osteocytes; marked alteration of

Address correspondence to: Naohisa Miyakoshi, $\mathrm{MD}, \mathrm{PhD}$ Department of Orthopedic Surgery, Akita University Graduate School of Medicine, 1-1-1 Hondo, Akita 010-8543, Japan

Tel: +81-18-884-6148, Fax: +81-18-836-2617

E-mail: miyakosh@doc.med.akita-u.ac.jp bone turnover; and non-skeletal mechanisms such as increased risk of falls (42). Glucocorticoids are also known to cause muscle weakness, in the form of "steroid myopathy" (21), and muscle weakness is considered one of the major risk factors for falls (29). Increased fall risk is associated with declines in muscle strength and, when combined with increased bone fragility, further increases the susceptibility of the individual to fracture (47). Natsui et al.(29) reported that patients with glucocorticoid treatment showed substantial loss of lean body mass, which mainly represents muscle volume, combined with decreased bone mineral density (BMD).

Vitamin D may have beneficial effects on fracture risk through increases in BMD (11) and/or improvements in muscle strength, thus decreasing the fall risk (6). Several recent meta-analyses have demonstrated that native or activated vitamin $\mathrm{D}$ have preventive effects on falls $(5,16)$. This preventive effect on falls contributes to reductions in fractures 
with vitamin $\mathrm{D}$ administration among elderly osteoporotic individuals $(4,32)$. However, whether vitamin D can exert positive effects on muscle function to prevent falls among patients receiving glucocorticoid therapy remains unclear.

Muscle weakness is determined by not only decreases in muscle strength, but also muscle fatigue. Contractile tension assessed by electrical stimulation can be used to evaluate skeletal muscle strength and fatigue in animal models $(3,13,37,43)$. Using this method, the present study investigated whether alfacalcidol $\left[1 \alpha(\mathrm{OH}) \mathrm{D}_{3}\right]$, an active vitamin $\mathrm{D}$ analog, exerts favorable effects on muscle strength and fatigue in glucocorticoid-treated rats. Preventive effects of alfacalcidol on muscle atrophy and bone loss in glucocorticoid-treated rats were also investigated.

\section{MATERIALS AND METHODS}

Animals and experimental protocol. Six-month-old female Wistar rats (Clea Japan Inc., Tokyo, Japan) were housed in a controlled environment (temperature, $23 \pm 2{ }^{\circ} \mathrm{C}$; humidity, $40 \pm 20 \%$ ) with a 12 -h lightdark cycle. Rats were allowed ad libitum access to tap water and commercial standard rodent chow (CE-7; Clea Japan Inc., Tokyo, Japan) (23, 30). Rats were randomized into the following four groups ( $\mathrm{n}=6-7$ each): 1) control group, administered vehicle of alfacalcidol and vehicle of prednisolone; 2) PSL group, administered prednisolone and vehicle of alfacalcidol; 3) D group, administered alfacalcidol and vehicle of prednisolone; and 4) PSL $+\mathrm{D}$ group, administered prednisolone and alfacalcidol.

Prednisolone (Predonine ${ }^{\circledR}$; Shionogi Pharmaceutical, Osaka, Japan) was dissolved in $0.9 \%$ saline and a dose of $10 \mathrm{mg} / \mathrm{kg} /$ day or vehicle (saline) alone was injected subcutaneously every day for 4 weeks. Prednisolone was chosen as a prototypical glucocorticoid used to manage many conditions in humans, such as rheumatoid arthritis, systemic lupus erythematosus, and bronchial asthma. The prednisolone dose was determined based on previous reports $(34,38)$. Alfacalcidol (Chugai Pharmaceutical, Tokyo, Japan) was dissolved in medium-chain triglyceride (MCT) and a dose of $0.1 \mu \mathrm{g} / \mathrm{kg} /$ day or vehicle (MCT) alone was administered orally every day for 4 weeks. The dose of alfacalcidol was determined based on a previous study showing that this dose did not elevate serum calcium levels (39).

Measurement of muscle strength and fatigability. Calf muscle strength and fatigue were measured the day after final administration of alfacalcidol and/or prednisolone or their vehicles. General anesthesia was induced by intraperitoneal injection of sodium pentobarbital $(30 \mathrm{mg} / \mathrm{kg}$ body weight). After opening the posterior surface of the right leg to expose the sciatic nerve in the gluteal region, a bipolar cuff electrode (inter-electrode distance, $5 \mathrm{~mm}$; MD Giken, Tokyo, Japan) was attached to the sciatic nerve (37) (Fig. 1). The rat was immobilized on a small platform with the knee in a fully extended position and fixed with Kirschner wire. The distal end of the Achilles tendon was exposed and cut at the insertion to the calcaneal bone. A transducer (Orientec, Tokyo, Japan) was attached and fixed next to the stump with a load of $1 \mathrm{~N}$ (37). Signals transmitted from the force transducer during isometric muscular contraction were recorded on a force-time curve using a paper recorder (Nihon Kohden, Tokyo, Japan) (37). To prevent muscle desiccation during the study, the exposed area was covered with mineral oil. The study was conducted at a constant room temperature of $25-27^{\circ} \mathrm{C}$. To obtain a tetanic contraction, muscle contraction was induced by a monophasic rectangular pulse with a frequency of $40 \mathrm{~Hz}$, a pulse width of $0.2 \mathrm{~ms}$, and a stimulation intensity of $-4 \mathrm{~V}$. Each stimulation took $180 \mathrm{~s}$. Stimulation conditions were determined according to our preliminary studies to

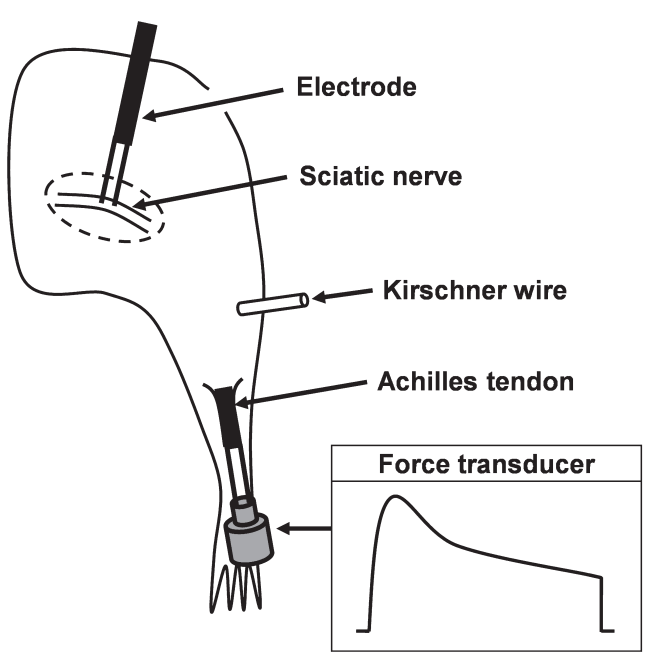

Fig. 1 Schematic illustration of the posterior right hindlimb, indicating the procedures for measurement of muscle strength and fatigue. The lower extremity was immobilized with the knee in a fully extended position and fixed with Kirschner wire. After exposing the sciatic nerve in the gluteal region, the stump of the Achilles tendon was attached to a transducer, then the sciatic nerve was stimulated with a bipolar cuff electrode. Signals transmitted from the force transducer during isometric muscular contraction were recorded. 
seek the optimal condition for glucocorticoid-treated rats (34).

Data from time points of $0,30,60$, and $180 \mathrm{~s}$ after the start of stimulation were used to evaluate muscle strength and fatigue. Muscle strength was defined as the maximum isometric contraction tension of the calf muscles normalized by the body weight of each animal (34). A strength decrement index (SDI) was used to assess muscle fatigue (9), calculated using the following formula: SDI (\%)= \{initial contractile tension in the period of stimulation (Ti) - contractile tension at each second from initial stimulation $(\mathrm{Tt})\} \times 100 / \mathrm{Ti}$. This formula provides the attenuation of torque from the beginning of stimulation. A high SDI indicates greater muscle fatigue.

Histological analysis of muscle. After determination of muscle strength, rats were euthanized by $\mathrm{CO}_{2}$ inhalation. The left tibialis anterior (TA) muscle was removed for histological analysis. TA muscles were chosen for this histological analysis because collection of the entire muscle without damage is easier for TA than for other muscles in the lower extremity. Muscles were rapidly frozen in 2-methylbutane (isopentane) and cooled in liquid nitrogen, then stored at $-80^{\circ} \mathrm{C}$ until analysis. Samples were then cut into $10-\mu \mathrm{m}$ thick transverse serial sections at the thickest part of the muscle belly, with the cryostat maintained at $-18^{\circ} \mathrm{C}$. Sections were stained using a histochemical method (adenosine triphosphatase) with preincubation at $\mathrm{pH}$ 4.4. To measure cross-sectional area (CSA) of muscle fibers, microscopic images with a magnification of $\times 200$ were captured digitally (BH-2; Olympus, Tokyo, Japan), and individual muscle fibers were traced on-screen using Image $\mathrm{J}$ image analysis software (National Institutes of Health, Bethesda, MD, USA). Areas of traced fibers were calculated using Image $\mathbf{J}$ software, based on a calibrated pixel-to-actual size $(\mu \mathrm{m})$ ratio. Five fields were randomly chosen, and 50 fibers per muscle were measured. With this method, intra-observer variations, as assessed by the coefficient of variation for five corresponding measurements in 10 randomly selected fibers, ranged from $0.67 \%$ to $3.4 \%$.
Inter-observer variations by 3 investigators, as assessed by the coefficient of variation of measurements in 10 randomly selected images, ranged from $1.1 \%$ to $4.3 \%$. Muscle fiber CSA based on muscle fiber phenotype (i.e., type I or type II fibers) was not measured in this study, as TA muscle in rats is almost exclusively composed of type II fibers.

$B M D$ measurement. At euthanasia, the right femur was harvested for BMD measurement. BMD at the proximal, middle, and distal thirds of the femur and total BMD of the femur were measured using dualenergy X-ray absorptiometry (QDR-4500 Delphi; Hologic, Bedford, MA, USA) (24).

Protocols for all animal experiments were approved in advance by the Animal Research Committee of Akita University, and all subsequent animal experiments adhered to the "Guidelines for Animal Experimentation" of the university.

Statistical analyses. All data are expressed as mean \pm standard deviation (SD). Differences between groups at each time point were evaluated using oneway analysis of variance (ANOVA). Two-way ANOVA (repeated-measures ANOVA) was performed to evaluate the roles of treatment and time in muscle strength and fatigue. Fisher's protected least significant difference test was used as a post hoc test for multiple comparisons. Comparisons of body weight in each group at the beginning and end of the experiment were performed using the paired $t$-test. All data were analyzed using Statcel2 statistical software (OMS, Saitama, Japan). Values of $P<0.05$ were considered significant.

\section{RESULTS}

Body weight

No significant differences in body weight were seen among the 4 groups at both the beginning and end of the experiment (Table 1).

\section{Muscle strength}

Muscle strength in all groups decreased in a timedependent manner under electric stimulation (Fig. 2).

Table 1 Body weight $(g)$

\begin{tabular}{llcccc}
\hline & Control & PSL & D & PSL+D & ANOVA* \\
\hline Beginning of experiment & $232 \pm 46$ & $238 \pm 44$ & $232 \pm 39$ & $238 \pm 33$ & 0.9865 \\
Upon sacrifice & $238 \pm 48$ & $232 \pm 40$ & $232 \pm 32$ & $227 \pm 49$ & 0.9588 \\
\hline * One-way analysis of variance & & & & \\
Data are presented as mean \pm SD. & & & &
\end{tabular}




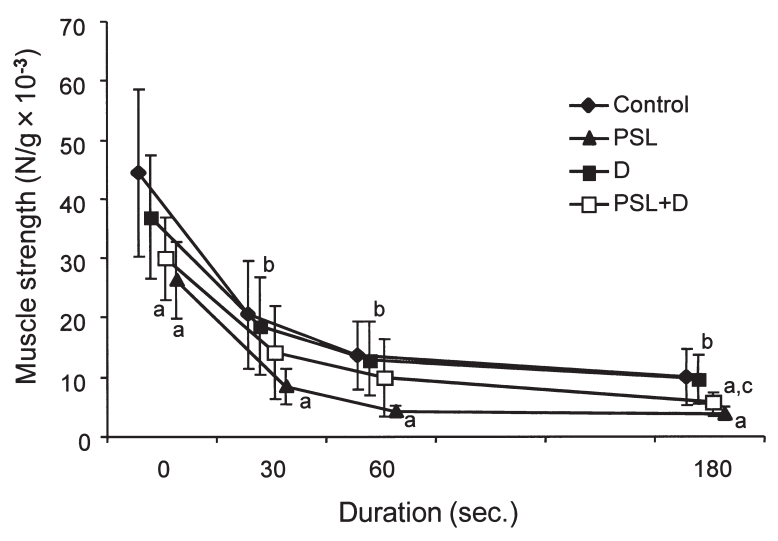

Fig. 2 Changes in muscle strength during stimulation. Each data point for Control $(\diamond)$, PSL $(\mathbf{\Delta})$, D $(\square)$, and PSL+D $(\square)$ groups is expressed as mean \pm SD. a,b,c Significant differences $(P<0.05)$ between: ${ }^{a}$ Control; ${ }^{b} \mathrm{PSL}$; and ${ }^{\mathrm{c}} \mathrm{D}$, at the same time point.

Two-way ANOVA showed significant differences in both the role of time $(P<0.0001)$ and the role of treatment $(P=0.0083)$. Post hoc testing for treatment showed that muscle strength was significantly lower in the PSL group than in control and D groups $(P=0.011$ and $P=0.009$, respectively). However, no significant differences in muscle strength were observed among control, D, and PSL+D groups.

Comparison of treatments at each time point by one-way ANOVA revealed significant differences in muscle strength among groups at the time points of $0,30,60$, and $180 \mathrm{~s}(P=0.0089, P=0.0257, P=$ 0.0087 , and $P=0.0034$, respectively). Significant differences between groups at these time points are shown in Fig. 2.

\section{Muscle fatigue}

SDI in all group increased in a time-dependent manner under electric stimulation (Fig. 3). Two-way ANOVA showed a significant difference in both the role of time $(P<0.0001)$ and the role of treatment $(P$ $=0.0207)$. Post hoc testing for the treatment showed that the SDI of the PSL group was significantly higher compared to the control, $\mathrm{D}$, and $\mathrm{PSL}+\mathrm{D}$ groups $(P=0.0209, P=0.0042$, and $P=0.0205$, respectively). However, no significant differences in SDI were observed among the control, D, and PSL $+\mathrm{D}$ groups.

Comparison of treatments at each time point by one-way ANOVA found significant differences in SDI among groups at the time point of $60 \mathrm{~s}(P=$ 0.0229). Significant differences between groups at this time point are shown in Fig. 3.

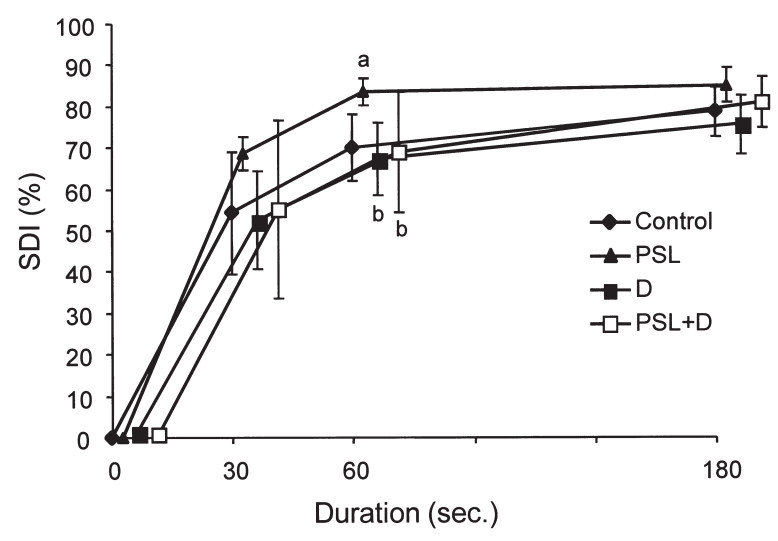

Fig. 3 Changes in SDI during stimulation. Each data point for Control $(\bullet)$, PSL $(\mathbf{\Delta})$, D ( $\mathbf{\square})$, and PSL+D ( $\square)$ groups is expressed as mean $\pm \mathrm{SD}$. ${ }^{\mathrm{a}, \mathrm{b}}$ Significant differences $(P$ $<0.05)$ between: ${ }^{a}$ Control; and ${ }^{b} \mathrm{PSL}$, at the same time point.

\section{CSA of muscle fibers}

CSA of TA muscle fibers was significantly smaller in the PSL group than in the other three groups (Fig. 4, Table 2). No significant differences in CSAs were seen among the control, D, and PSL $+\mathrm{D}$ groups.

\section{$B M D$}

BMD of the proximal and distal thirds of the femur (cancellous bone-rich sites), and of the total femur were significantly less in the PSL group than in the other three groups (Table 3). However, BMD of the middle third of the femur (cortical bone-rich site) showed no significant difference among groups. No significant differences among control, D, and $\mathrm{PSL}+\mathrm{D}$ groups were seen for any BMD measurement sites.

\section{DISCUSSION}

Glucocorticoids stimulate muscle proteolysis $(10,22)$ and inhibit protein synthesis $(10,41)$, resulting in muscle atrophy and muscle dysfunction. Glucocorticoid-induced myopathy is characterized by a decrease in the size of muscle fibers (13). In the present study, glucocorticoid treatment caused a $31 \%$ decrease in mean muscle fiber CSA of TA muscle compared to controls. These findings are similar to previous animal studies, which have shown a $26 \%$ decrease in extensor digitorum longus and soleus muscles in rats (22) and a $26 \%$ decrease in diaphragm muscle in hamsters (18) after glucocorticoid administration.

Muscle weakness of the lower extremity has been recognized as an important factor contributing to 

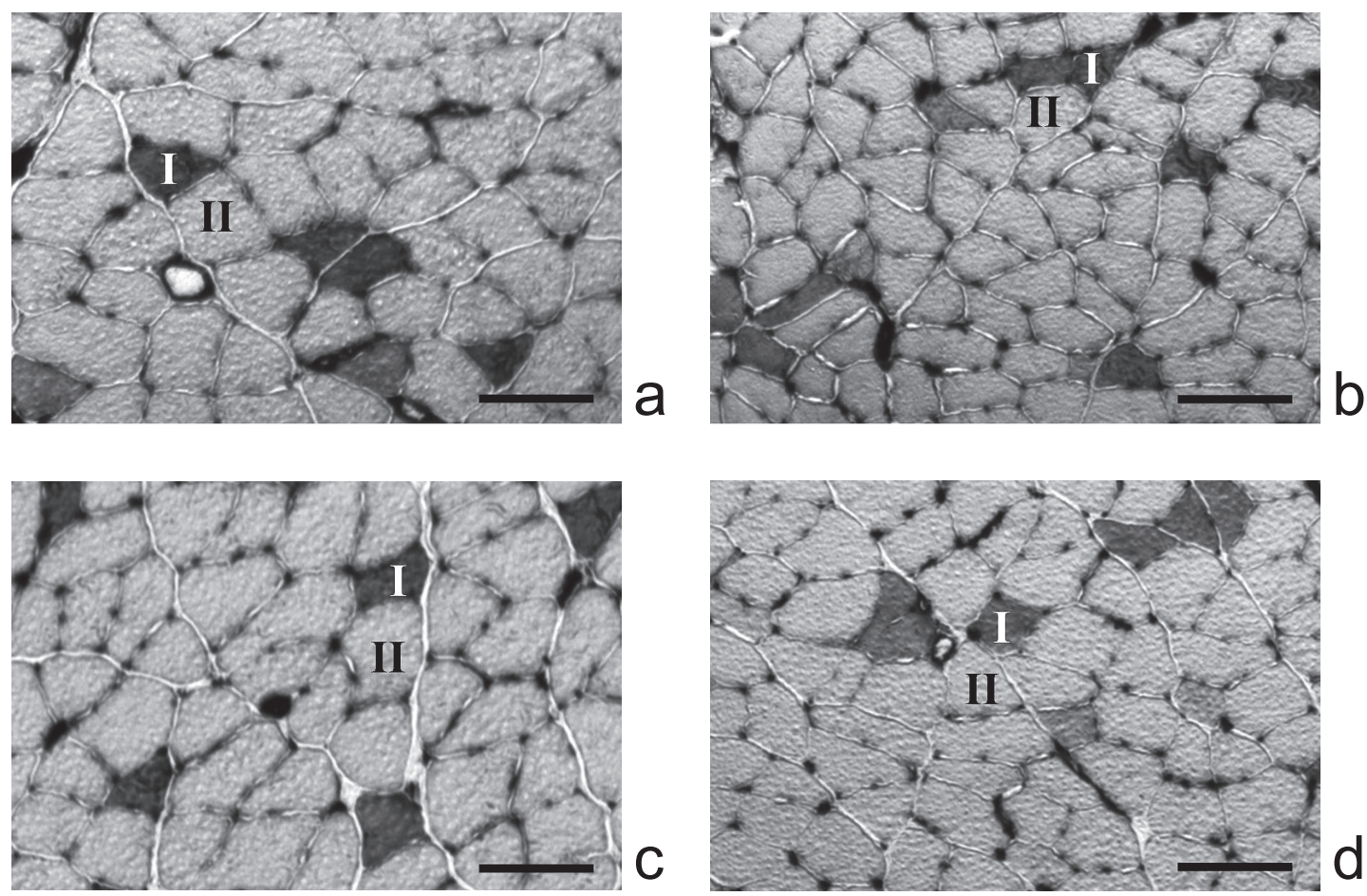

Fig. 4 Histological changes in the tibialis anterior muscle of rats treated with prednisolone (PSL) and/or alfacalcidol (D). (a) a control rat; (b) a rat treated with PSL; (c) a rat treated with D; (d) a rat treated with PSL+D. A rat treated with PSL showing substantial decrease in cross-sectional area of muscle fibers. Adenosine triphosphatase stain (original magnification, $\times 200)$. I, type I fibers; II, type II fibers. Bar: $100 \mu \mathrm{m}$.

Table 2 Cross-sectional area (CSA) of tibialis anterior muscle fibers $\left(\mu \mathrm{m}^{2}\right)$

\begin{tabular}{cccccc}
\hline & Control & PSL & D & PSL+D & ANOVA* \\
\hline CSA & $2197 \pm 720$ & $1509 \pm 534^{\mathrm{a}}$ & $2194 \pm 1141^{\mathrm{b}}$ & $1978 \pm 932^{\mathrm{b}}$ & 0.0003 \\
\hline
\end{tabular}

* One-way analysis of variance

${ }^{\mathrm{a}, \mathrm{b}}$ Significant differences $(P<0.05)$ between: ${ }^{\mathrm{a}}$ Control; and ${ }^{\mathrm{b}} \mathrm{PSL}$.

Data are presented as mean \pm SD.

Table 3 Bone mineral density (BMD) of femur $\left(\mathrm{g} / \mathrm{cm}^{2}\right)$

\begin{tabular}{lclllc}
\hline & Control & \multicolumn{1}{c}{ PSL } & \multicolumn{1}{c}{ D } & \multicolumn{1}{c}{ PSL + D } & ANOVA* \\
\hline Proximal BMD & $0.256 \pm 0.008$ & $0.239 \pm 0.008^{\mathrm{a}}$ & $0.265 \pm 0.012^{\mathrm{b}}$ & $0.257 \pm 0.009^{\mathrm{b}}$ & 0.0011 \\
Middle BMD & $0.255 \pm 0.009$ & $0.248 \pm 0.011$ & $0.263 \pm 0.012$ & $0.255 \pm 0.013$ & 0.1965 \\
Distal BMD & $0.285 \pm 0.007$ & $0.266 \pm 0.017^{\mathrm{a}}$ & $0.295 \pm 0.014^{\mathrm{b}}$ & $0.283 \pm 0.005^{\mathrm{b}}$ & 0.0043 \\
Total BMD & $0.264 \pm 0.006$ & $0.251 \pm 0.009^{\mathrm{a}}$ & $0.273 \pm 0.012^{\mathrm{b}}$ & $0.264 \pm 0.008^{\mathrm{b}}$ & 0.0033 \\
\hline
\end{tabular}

* One-way analysis of variance

${ }^{\mathrm{a}, \mathrm{b}}$ Significant differences $(P<0.05)$ between: ${ }^{\mathrm{a} C o n t r o l}$; and ${ }^{\mathrm{b}} \mathrm{PSL}$.

Data are presented as mean $\pm \mathrm{SD}$.

risk of falls (26). Muscle fatigue could also represent a potential risk factor for slip-induced falls (31). Glucocorticoid administration in the present study decreased maximum contractile strength and increased muscle fatigability. Many muscle properties change during fatigue, including action potential, extracellular and intracellular ion concentrations (46), and levels of many intracellular metabolites (1, 28). In the traditional explanation, accumulation of intracellular lactate and hydrogen ions causes impairment of contractile proteins (20). Glucocorticoid treatment reportedly results in a significant decrease 
in phosphofructokinase (PFK), an important enzyme for anaerobic energy production, in skeletal muscle (25). Decreased PFK activity may thus result in increased muscle fatigability in glucocorticoid-treated rats.

In the present study, calf muscles were electrically stimulated for $180 \mathrm{~s}$ at $40 \mathrm{~Hz}$. This stimulation condition was determined based on our preliminary studies with glucocorticoid-treated rats (34). Type I muscle fibers (slow-twitch muscle) are known to be stimulated at a lower frequency $(10-20 \mathrm{~Hz})$ than type II muscle fibers (fast-twitch muscle; 30-60 Hz) depending on the nerve supply (17). Among several stimulatory conditions ranged from 20 to $100 \mathrm{~Hz}$, our preliminary studies identified stimulation at $40 \mathrm{~Hz}$ as the best condition to show differences in muscle strength and fatigue between controls and glucocorticoid-treated rats (34). This is probably because glucocorticoid-induced myopathy is characterized by atrophy of type II muscle fibers (13). We have thus determined $40-\mathrm{Hz}$ stimulation represents the optimal condition for drug intervention in glucocorticoid-treated rats (34).

To the best of our knowledge, no previous studies have examined the effects of vitamin D or its active analogues on skeletal muscle strength and fatigue in glucocorticoid-treated animals. In the present study, alfacalcidol prevented not only decreases in BMD, but also muscle atrophy and muscle fatigue, and preserved muscle strength in glucocorticoid-treated rats. The mechanisms by which alfacalcidol exerts these effects on muscles in glucocorticoid-treated rats remain unclear. However, various lines of evidence regarding effects of vitamin $\mathrm{D}$ on muscles have been reported. Vitamin D receptors have been identified in skeletal muscle tissue (14), and recent studies have shown that vitamin D inadequacy is a factor in loss of muscle mass and muscle strength (44), increased body sway, increased risk of falls, and fall-related fractures (33). Sprensen et al. (40) showed an increase in relative fiber composition and in size of type II fibers after treatment with alfacalcidol and calcium using muscle biopsies from elderly women. In a randomized controlled study by Sato et al.(35), treatment of elderly stroke patients with vitamin D increased type II muscle fiber diameter and the percentage of type II fibers over a 2-year period.

In addition to the effects of vitamin D on muscle morphology, several genomic and non-genomic effects of vitamin D in muscle have been reported. As genomic effects, $1 \alpha, 25(\mathrm{OH})_{2} \mathrm{D}_{3}$ regulates muscle calcium uptake (7), affects the synthesis of muscle cytoskeletal proteins (8), and regulates phosphate metabolism in myoblasts (8). A recent study revealed that $1 \alpha, 25(\mathrm{OH})_{2} \mathrm{D}_{3}$ also affects muscle function through a transcription-enhancing role on proteins such as insulin-like growth factor (IGF)-I and its binding proteins, in addition to direct involvement in calcium metabolism, thus indicating an anabolic effect on muscle tissue (19). IGF-I induces proliferation, differentiation and hypertrophy of skeletal muscle (2). Conversely, as non-genomic effects in muscle, $1 \alpha, 25(\mathrm{OH})_{2} \mathrm{D}_{3}$ activates protein kinase $\mathrm{C}$ to release calcium into the cytosol $(12,27)$ and stimulates protein synthesis in muscle cells (36). These effects of vitamin D could also be exerted even under glucocorticoid treatment.

Several limitations in the present study warrant attention. First, the duration of treatment with alfacalcidol was only 4 weeks, although the length of treatment was determined based on previous studies (24). Duration of treatment appears to represent an important factor, and the effects of vitamin D treatment on muscles in glucocorticoid-treated animals should be further clarified in future studies by increasing the duration of administration. Second, the present study did not measure muscle fiber CSA based on muscle fiber phenotype, as TA muscle in rats is almost exclusively composed of type II fibers. Although glucocorticoids are known to cause muscle atrophy of fast-twitch (type II) muscle fibers (13), the effects of glucocorticoids on muscle fiber phenotypes in other muscles should be evaluated in future studies.

In conclusion, the present study demonstrated that alfacalcidol treatment in glucocorticoid-treated rats prevented not only decreases in BMD, but also muscle atrophy and muscle fatigue, and preserved muscle strength. Administration of alfacalcidol may have positive effects on skeletal muscles in patients treated with glucocorticoids, in addition to the known effects on bone metabolism.

\section{REFERENCES}

1. Allen DG, Lamb GD and Westerblad H (2008) Skeletal muscle fatigue: cellular mechanisms. Physiol Rev 88, 287-332.

2. Barton-Davis ER, Shoturma DI, Musaro A, Rosenthal N and Sweeney HL (1998) Viral mediated expression of insulin-like growth factor I blocks the aging-related loss of skeletal muscle function. Proc Natl Acad Sci USA 95, 15603-15607.

3. Beiner JM, Jok1 P, Cholewicki J and Panjabi MM (1999) The effect of anabolic steroids and corticosteroids on healing of muscle contusion injury. Am J Sports Med 27, 2-9.

4. Bischoff HA, Stähelin HB, Dick W, Akos R, Knecht M, Salis C, Nebiker M, Theiler R, Pfeifer M, Begerow B, Lew RA and Conzelmann M (2003) Effects of vitamin D and calcium 
supplementation on falls: a randomized controlled trial. $J$ Bone Miner Res 18, 343-351.

5. Bischoff-Ferrari HA, Borchers M, Gudat F, Dürmüller U, Stähelin HB and Dick W (2004) Vitamin D receptor expression in human muscle tissue decreases with age. $J$ Bone Miner Res 19, 265-269.

6. Bischoff-Ferrari HA, Dawson-Hughes B, Willett WC, Staehelin HB, Bazemore MG, Zee RY and Wong JB (2004) Effect of vitamin D on falls: a meta-analysis. JAMA 291, 1999-2006.

7. Boland R (1986) Role of vitamin D in skeletal muscle function. Endocr Rev 7, 434-448.

8. Boland R, de Boland AR, Marinissen MJ, Santillan G, Vazquez G and Zanello S (1995) Avian muscle cells as targets for the secosteroid hormone 1,25-dihydroxy-vitamin $\mathrm{D}_{3}$. Mol Cell Endocrinol 114, 1-8.

9. Clarke HH, Shay CT and Mathews DK (1954) Strength decrement of elbow flexor muscles following exhaustive exercise. Arch Phys Med Rehabil 35, 560-567.

10. Dardevet D, Sornet C, Savary I, Debras E, Patureau-Mirand P and Grizard J (1998) Glucocorticoid effects on insulin- and IGF-I-regulated muscle protein metabolism during aging. $J$ Endocrinol 156, 83-89.

11. Dawson-Hughes B, Harris SS, Krall EA and Dallal GE (1997) Effect of calcium and vitamin D supplementation on bone density in men and women 65 years of age or older. $N$ Engl $J$ Med 337, 670-676.

12. de Boland AR and Boland RL (1993) 1,25-Dihydroxyvitamin D-3 induces arachidonate mobilization in embryonic chick myoblasts. Biochim Biophys Acta 1179, 98-104.

13. Dekhuijzen PN, Gayan-Ramirez G, de Bock V, Dom R and Decramer M (1993) Triamcinolone and prednisolone affect contractile properties and histopathology of rat diaphragm differently. J Clin Invest 92, 1534-1542.

14. DeLuca HF (2004) Overview of general physiologic features and functions of vitamin D. Am J Clin Nutr 80, 1689S1696S.

15. Doga M, Mazziotti G, Bonadonna S, Patelli I, Bilezikian JP, Canalis E and Giustina A (2008) Prevention and treatment of glucocorticoid-induced osteoporosis. J Endocrinol Invest 31, $53-58$.

16. Dukas L, Bischoff HA, Lindpaintner LS, Schacht E, BirknerBinder D, Damm TN, Thalmann B and Stähelin HB (2004) Alfacalcidol reduces the number of fallers in a communitydwelling elderly population with a minimum calcium intake of more than $500 \mathrm{mg}$ daily. J Am Geriatr Soc 52, 230-236.

17. Eccles JC, Eccles RM and Lundberg A (1958) The action potentials of the alpha motoneurones supplying fast and slow muscles. J Physiol 142, 275-291.

18. Fournier M, Huang ZS, Li H, Da X, Cercek B and Lewis MI (2003) Insulin-like growth factor I prevents corticosteroidinduced diaphragm muscle atrophy in emphysematous hamsters. Am J Physiol Regul Integr Comp Physiol 285, R34-43.

19. Hamilton B (2010) Vitamin D and human skeletal muscle. Scand J Med Sci Sports 20, 182-190.

20. Hogan MC, Gladden LB, Kurdak SS and Poole DC (1995) Increased [lactate] in working dog muscle reduces tension development independent of pH. Med Sci Sports Exerc 27, 371-377.

21. Kanda F, Okuda S, Matsushita T, Takatani K, Kimura KI and Chihara K (2001) Steroid myopathy: pathogenesis and effects of growth hormone and insulin-like growth factor-I administration. Horm Res 56, S24-28.

22. Kanda F, Takatani K, Okuda S, Matsushita T and Chihara K (1999) Preventive effects of insulinlike growth factor-I on steroid-induced muscle atrophy. Muscle Nerve 22, 213-217.

23. Kasukawa Y, Miyakoshi N, Itoi E, Tsuchida T, Tamura Y, Kudo T, Suzuki K, Seki A and Sato K (2004) Effects of h-PTH on cancellous bone mass, connectivity, and bone strength in ovariectomized rats with and without sciatic-neurectomy. J Orthop Res 22, 457-464.

24. Kasukawa Y, Miyakoshi N, Maekawa S, Nozaka K, Noguchi $\mathrm{H}$ and Shimada Y (2010) Effects of alfacalcidol on muscle strength, muscle fatigue, and bone mineral density in normal and ovariectomized rats. Biomed Res 31, 273-279.

25. Lieu FK, Powers SK, Herb RA, Criswell D, Martin D, Wood C, Stainsby W and Chen CL (1993) Exercise and glucocorticoid-induced diaphragmatic myopathy. J Appl Physiol 75, $763-771$.

26. Moreland JD, Richardson JA, Goldsmith $\mathrm{CH}$ and Clase CM (2004) Muscle weakness and falls in older adults: a systematic review and meta-analysis. J Am Geriatr Soc 52, 11211129.

27. Morelli S, de Boland AR and Boland RL (1993) Generation of inositol phosphates, diacylglycerol and calcium fluxes in myoblasts treated with 1,25-dihydroxyvitamin $\mathrm{D}_{3}$. Biochem $J$ 289, 675-679.

28. Munkvik M, Lunde PK and Sejersted OM (2009) Causes of fatigue in slow-twitch rat skeletal muscle during dynamic activity. Am J Physiol Regul Integr Comp Physiol 297, R900910.

29. Natsui K, Tanaka K, Suda M, Yasoda A, Sakuma Y, Ozasa A, Ozaki S and Nakao K (2006) High-dose glucocorticoid treatment induces rapid loss of trabecular bone mineral density and lean body mass. Osteoporos Int 17, 105-108.

30. Nozaka K, Miyakoshi N, Kasukawa Y, Maekawa S, Noguchi $\mathrm{H}$ and Shimada Y (2008) Intermittent administration of human parathyroid hormone enhances bone formation and union at the site of cancellous bone osteotomy in normal and ovariectomized rats. Bone 42, 90-97.

31. Parijat P and Lockhart TE (2008) Effects of quadriceps fatigue on the biomechanics of gait and slip propensity. Gait Posture 28, 568-573.

32. Pfeifer M, Begerow B, Minne HW, Abrams C, Nachtigall D and Hansen C (2000) Effects of a short-term vitamin D and calcium supplementation on body sway and secondary hyperparathyroidism in elderly women. J Bone Miner Res 15, $1113-1118$.

33. Pfeifer M, Begerow B, Minne HW, Schlotthauer T, Pospeschill M, Scholz M, Lazarescu AD and Pollähne W (2001) Vitamin D status, trunk muscle strength, body sway, falls, and fractures among 237 postmenopausal women with osteoporosis. Exp Clin Endocrinol Diabetes 109, 87-92.

34. Sasaki H, Miyakoshi N, Kasukawa Y, Maekawa S, Noguchi H, Kamo K and Shimada Y (2009) Muscle strength and fatigue in glucocorticoid-treated rats. Akita J Med 36, 195-202.

35. Sato Y, Iwamoto J, Kanoko T and Satoh K (2005) Low-dose vitamin D prevents muscular atrophy and reduces falls and hip fractures in women after stroke: a randomized controlled trial. Cerebrovasc Dis 20, 187-192.

36. Selles J and Boland R (1991) Rapid stimulation of calcium uptake and protein phosphorylation in isolated cardiac muscle by 1,25-dihydroxyvitamin $\mathrm{D}_{3}$. Mol Cell Endocrinol 77, $67-73$.

37. Shimada Y, Ito H, Matsunaga T, Misawa A, Kawatani M and Itoi E (2006) Reduction of muscle fatigue by catchlikeinducing intermittent electrical stimulation in rat skeletal muscle. Biomed Res 27, 183-189.

38. Shin YS, Fink H, Khiroya R, Ibebunjo C and Martyn J (2000) 
Prednisolone-induced muscle dysfunction is caused more by atrophy than by altered acetylcholine receptor expression. Anesth Analg 91, 322-328.

39. Shiraishi A, Takeda S, Masaki T, Higuchi Y, Uchiyama Y, Kubodera N, Sato K, Ikeda K, Nakamura T, Matsumoto T and Ogata E (2000) Alfacalcidol inhibits bone resorption and stimulates formation in an ovariectomized rat model of osteoporosis: distinct actions from estrogen. J Bone Miner Res 15, 770-779.

40. Sprensen OH, Lund B, Saltin B, Lund B, Andersen RB, Hjorth L, Melsen F and Mosekilde L (1979) Myopathy in bone loss of ageing: improvement by treatment with 1 alphahydroxycholecalciferol and calcium. Clin Sci (Lond) 56, $157-161$.

41. Tomas FM (1998) The anti-catabolic efficacy of insulin-like growth factor-I is enhanced by its early administration to rats receiving dexamethasone. J Endocrinol 157, 89-97.

42. Van Staa TP, Leufkens HG, Abenhaim L, Zhang B and Cooper C (2000) Use of oral corticosteroids and risk of fractures. J Bone Miner Res 15, 993-1000.
43. Viires N, Pavlovic D, Pariente R and Aubier M (1990) Effects of steroids on diaphragmatic function in rats. Am Rev Respir Dis 142, 34-38.

44. Visser M, Deeg DJ and Lips P (2003) Low vitamin D and high parathyroid hormone levels as determinants of loss of muscle strength and muscle mass (sarcopenia): the Longitudinal Aging Study Amsterdam. J Clin Endocrinol Metab 88, 5766-5772.

45. Wallach S, Cohen S, Reid DM, Hughes RA, Hosking DJ, Laan RF, Doherty SM, Maricic M, Rosen C, Brown J, Barton I and Chines AA (2000) Effects of risedronate treatment on bone density and vertebral fracture in patients on corticosteroid therapy. Calcif Tissue Int 67, 277-285.

46. Westerblad H, Lee JA, Lamb AG, Bolsover SR and Allen DG (1990) Spatial gradients of intracellular calcium in skeletal muscle during fatigue. Pflugers Arch 415, 734-740.

47. Youm T, Koval KJ, Kummer FJ and Zuckerman JD (1999) Do all hip fractures result from a fall? Am J Orthop (Belle Mead NJ) 28, 190-194. 